these topics are interspersed with appropriate basic mathematical-physical sections, for example, on principles of registration, on elasticity and flow and even on the rate of ageing of a space traveller including a discussion of the clock paradox. To appreciate the value of this book the reader must have an intimate knowledgo of the techniques and the problems of interpretation which arise in the course of their use, because there are few experimental details given. Possibly for the first time, however, the theoretical basis for much of the discussion in the current literature is collected togother. References are given up to late 1969 so that the author is in very close touch with the subject. Against this background, volume two is a most impressive work. Anybody involved in cardiovascular research will find much to stimulate him and interest him in treating his observations quantitatively so as to obtain as much from them as possible.

R. G. GosLing

C. B. Altsopy

\section{THE BURKILLS'S ANALYSIS}

\section{A Second Course in Mathematical Analysis}

By J. C. Burkill and H. Burkill. Pp. vii +526. (Cambridge University Press: London, March 1970.) 80s; $\$ 12 \cdot 50$.

THE writing of a "second course" in analysis demands a nice sense of balance: there must be consolidation, and there must be exploration; manipulative technique must bo strengthened but elaborate gymnastics avoided; acquaintance with modern concepts must be made while perhaps mitigating the more austere abstractions of Choquet and Dieudonné. 'The Burkill collaboration has shown admirable judgment in mecting such requirements, and the result is a book which, for the English reader, has no superior and few equals.

Much of the tone is set by the first four chaptors in which, after some recapitulation of set theory, the con. cepts and simplex properties of general metric spaces are introduced, not merely as generalizations but as potent coordinating themes for the later work: the completeness and the compactness of a metric space, with corollaries such as the Banach fixed-point theorem, supply a remarkable cohesion and simplification in many parts of real variable theory. For example, that powerful doublelimit theorem of Tannery's, over which undergraduates 50 years ago spent much toil and sweat, can now be lightly offered among the exercises for the reader. Again, in dealing with functions of several variables, where the theorems concerning implicit functions and inverse functions are important if tiresome, the metric space approach, together with the authors' precision of language and shrewd choice of symbolism, enable the reader to get a firm grasp of this topic.

The elements of integration have been dealt with in the "first course". The treatment hero has two surprises. 'The work begins with the Riemann-Stieltjes integral, and the main properties are obtained, as far as Riesz's theorem which relates a continuous linear function to a function of bounded variation. The Riemann integral follows as a special case, and its identity with the integral as defined in the "first course" is established. The second surprise is the omission of the Lobesgue integral; the authors explain that to have included an adequate account would have upset the balance of the book. Moreover, the senior author's excellent Cambridge tract is readily available. The loss, though it will be deplored, is not great; even in dealing with Fourier series, while the expert may detect places where the Lebesgue integral would have provided a more finished and satisfactory theory, the novice will hardly feol any deprivation.

The chapters on complex analysis are fairly straightforward, with modern concepts and terminology used where desirable. Cauchy's theorem and the stream of consequences are clearly expounded, and the applications to special functions include a useful introduction to asymptotic expansions. Every teacher of analysis will have his own pet topic which ought to have been included but isn't; it would be much more difficult to mention a topic which is included but should not be.

'The authors have obviously taken great pains over the tedious task of providing a plenitude of exereises which are neither routine drill nor chunks of important bookwork for which room could not be found in the text; but they have placed the conscientious student still further in their debt by supplying answers and copious hints. The notes at the end of each chapter give historical references, alternative developments and suggestions for further reading.

T. A. A. BROADBENT

\section{GREEN'S FUNCTIONS}

\section{Green's Functions}

Introductory Theory with Applications. By G. F. Roach. (The New University Mathematics Series.) Pp. xii +279. (Van Nostrand Reinhold: London and New York, January 1970.) 90s.

From the title one would expect this book to be devoted almost entirely to the elementary theory of Green's functions and the applieations of this theory. This, howcver, is not the case and more than half the book consists of background material: vector spaces, linear transformations in spaces of finite dimension, continuous functions, integral operators, generalized Fourier series and integral equations.

The inclusion of such a large amount of background material has resulted in a book which will have great difficulty in inducing in the general reader any interest or understanding of Grcen's functions and their usefulness in the solution of boundary value problems.

The concept of the Green's function is introduced in the very brief introductory chapter in which the author considers the forced transverse oscillations of a stretched string, and demonstrates how the Green's function arises naturally in this problem. The effect of this chapter is nullified, however, by the last sentence, which seems to suggest that to achieve a better grasp of the concept of the Green's function it is necessary to read the next five chapters. It is very doubtful whether many engineers and physicists (or, indeed, mathematicians) will have the perseverance to do this and they are very likely to give up before the scventh and ninth chapters where the Green's functions for ordinary and partial differential equations, respectively, are discussed in detail. The material in these two chapters is well presented in a fairly standard fashion and $I$ feel that most of it could have been written so as to be comprehensible without reading most of the preceding chapters. It would also have been moro satisfactory if greater attention had been paid to the explicit calculation of Green's functions for partial differential equations.

This book cannot really be recommended as providing a good method of achieving reasonable familiarity with even the elementary theory of Green's functions, and I feel that a much shorter monograph presented in a slightly more intuitive fashion would have been considerably more useful.

W. E. WILLIAMS

\section{DIELECTRICS}

\section{Dielectric Properties and Molecular Behaviour}

By Nora E. Hill, Worth E. Vaughan, A. H. Price and Mansel Davies. (Van Nostrand Series in Physical Chemistry.) Pp. xiil +480. (Van Nostrand Reinhold: London and New York, July 1969.) $130 \mathrm{~s}$.

THIs book is devoted to an important branch of science that is of interest to physicists, chemists, molecular biologists and enginecrs. Dielectrics is a subject which, at its best, involves much interplay of theory and experiment. 